Cad.Est.Ling., Campinas, (45):69-77, Jul./Dez. 2003

\title{
O ESTATUTO DA NARRATIVA ORAL NO DESENVOLVIMENTO DA LINGUAGEM DE CRIANÇAS NO CONTEXTO PATOLÓGICO SOB UMA PERSPECTIVA DISCURSIVA
}

\author{
SILVANA PEROTINO \\ (UNIMEP/UNICAMP)
}

\begin{abstract}
This paper intends to examine the consequences of a discursive approach language to the therapeutic processes of psychotic children. The linguistic transformations observed in the children language are postulate to the narrative context. The effects of deviant child language on the other determine the status of patient as speaker.
\end{abstract}

\section{A CONSTITUIÇÃO DOS CAMPOS DE SABERES}

A reflexão sobre o estatuto da narrativa oral no contexto patológico, especificamente na clínica fonoaudiológica, parece não permitir que se fuja da historicização dessa área. Esta constatação vem do fato de existirem movimentos na área clamando por análises criteriosas acerca dos empréstimos que, desde o seu início, se tem feito de outras disciplinas, no caso, da Medicina, da Lingüística e da Psicologia/Pedagogia. Nas recapitulações históricas sobre a origem da Fonoaudiologia no Brasil na década de trinta (Berberian, 1995), testemunha-se a sua inscrição como área de saber afeito à padronização dos padrões de fala da população, traduzido pela participação de professores, os primeiros reeducadores da fala, em um congresso que discutia formas de unificar a língua nacional. Uma análise crítica desse momento histórico deixa entrever interesses econômicos, políticos, pois a existência de vários dialetos em uma língua diminuiria, por exemplo, o controle social do Estado sobre a população. Relatar esse episódio no escopo desse trabalho, cuja discussão é sobre o estatuto da narrativa oral no contexto patológico, significa demarcar o lugar em que a clínica fonoaudiológica vem se constituindo: ela tem negligenciado o subjetivo por ocupar-se com um padrão de normalidade suposto; creditando os "erros", "desvios" encontrados na linguagem do indivíduo à falta de recursos internos (orgânicos) e/ou externos (estimulação ambiental).

Arantes (1994) em seu texto "O fonoaudiólogo, este aprendiz de feiticeiro", acaba sintetizando as influências das áreas supracitadas da seguinte forma: no paradigma da clínica fonoaudiológica tradicional, a entrevista fonoaudiológica segue os moldes da anamnese médica, ou seja, descreve-se a queixa e se arrola o histórico da doença da criança por meio da aplicação de um questionário aos pais/mãe (responsável); já a avaliação, pauta-se sobre testes de linguagem, cuja influência é postulada à lingüística gerativa, já que um sujeito "ideal” capaz de interpretar e produzir sentenças em ordem de complexidade crescente é pressuposto. Na junção dessas áreas de conhecimento, procura-se estabelecer o diagnóstico etiológico (alguma disfunção orgânica reportada na entrevista justificaria o problema da criança) e nosográfico (a falta de respostas lingüístico-cognitivas, esperadas para a idade, permite estabelecer uma classificação para o problema encontrado). No terceiro momento, o fonoaudiólogo dessa perspectiva se incube de ensinar o que falta na linguagem dessa criança. Não por acaso, nesse momento a influência marcante vem da área pedagógica, da qual a fórmula ensinoaprendizagem como transmissão de saber do professor para o aluno se resgata. Na terapêutica da 
linguagem também se inclui a vertente behaviorista da psicologia, já que para se obter resposta correta, de acordo com padrão de fala esperado para a idade da criança, lança-se mão da modelagem do comportamento verbal.

Deve-se salientar que as reflexões da autora sobre os três momentos da clínica fonoaudiológica são realizadas tendo como ponto de partida o acompanhamento de uma criança que não fala, com diagnóstico de atraso de linguagem. Os fatores causais dessa alteração, assim como a terapêutica a ser seguida, quando não fazendo parte de outras doenças, como a paralisia cerebral, a deficiência mental, entre outras (portanto, explicada basicamente pela deficiência primária apresentada), são buscados de acordo com a concepção de linguagem do clínico, mesmo que ele não tenha consciência desse fato.

Arantes observa que os empréstimos de outras áreas do saber pela fonoaudiologia muitas vezes são pura incorporação, sem uma reflexão mais exaustiva. Esquematicamente, a ausência de fala na criança seria explicada do ponto de vista behaviorista pela falta de estimulação ambiental; na inatista, ao contrário, a questão seria de ordem maturacional e por interferência de fatores orgânicos. Já os cognitivistas explicariam o atraso de linguagem como decorrente de falhas na formação dos esquemas de ação pela criança, responsáveis pelo desenvolvimento de capacidades cognitivas consideradas pré-requisitos para o aparecimento da função simbólica.

Nesse ponto vale a pena destacar dois fatos fundamentais na historicização da área fonoaudiológica: as formas como foram realizados os empréstimos e o fato de que os movimentos daí oriundos estabeleceram continuidades e rupturas de paradigmas. A continuidade dentro da área vem sendo nomeada de clínica fonoaudiológica tradicional e a ruptura, que no seu bojo mina com conceitos implícitos nas três concepções de linguagem já citadas, tais como: sujeito uno e consciente, língua como sistema fechado, literalidade do sentido, intencionalidade do dizer, é reconhecida como clínica fonoaudiológica na perspectiva discursiva.

Pode-se afirmar que a clínica fonoaudiológica na perspectiva discursiva (re)interpreta conceitos oriundos basicamente de duas áreas da Lingüística, da Aquisição da Linguagem e da Análise do Discurso (Arantes, op. cit.). As interpretações nessa perspectiva de clínica sobre as contribuições da Medicina e da Pedagogia para a Fonoaudiologia são um capítulo à parte, já que procurarão se coadunar, dentro do possível, com perspectivas dessas áreas que não sejam ou racionalistas ou empiristas.

A perspectiva em Aquisição de Linguagem que permitiu olhar e escutar de outra maneira o discurso da criança e de sua família na clínica de linguagem foi a do sociointeracionismo. Na historicização que M. T. Lemos (1994) faz desta área, interpretando as relações entre a Psicolingüística e a Lingüística, ela inicia focalizando a inauguração da Psicolingüística em 1954, apontando para o nascimento de uma ciência de certo modo atípico, já que não condizente com o surgimento das disciplinas científicas, já que somente depois de passado o momento de ruptura dos paradigmas vigentes se reconhece o início da história de uma ciência (Maia, 1985, apud Lemos, 1994). No caso, psicólogos e lingüistas, reunidos naquela data em um seminário, resolveram fundir num só quadro conceitual três áreas que abordavam o processo de linguagem: a lingüística estrutural americana, a teoria da aprendizagem e a teoria da comunicação.

$\mathrm{Na}$ análise interpretativa da disciplina são reconhecidas pela autora três fases. Na primeira fase da Psicolingüística, a demanda parte da Psicologia, que buscava romper com o discurso alicerçado sobre o sujeito consciente e que, em razão das capacidades de percepção e de conhecimento, estabelece relação com o mundo. Entretanto, ao tentar destacar a supremacia da língua sobre o sujeito, acabou reduzindo a linguagem a um comportamento entre outros, e, além disso, a criança passou a ser vista tal qual um adulto, só que menos preparada. A segunda fase da disciplina, de inspiração chomskyana, fornece vida curta à primeira, reconhecidamente comportamentalista, por privilegiar o que é da ordem do lingüístico. A linguagem na visão de Chomsky é inata, estando inscrita na mente do 
falante, e dotando-o de capacidade para produzir e interpretar frases não ouvidas anteriormente, ou seja, a sua perspectiva é racionalista: o seu interesse recai por aquilo que ele denominou de competência, precisamente a gramática universal, em contraposição ao desempenho, domínio da performance. Nesse sentido, as pesquisas da área se voltaram para descrição da gramática da criança, acreditando que, ao se utilizar este procedimento, estariam descrevendo o desenvolvimento da gramática universal em graus de complexidade. Contudo, os pesquisadores cometerem um erro, pois, como mostra Lemos (op. cit.), o inatismo recusa as noções de sujeito empírico e de estágios de desenvolvimento, próprias da Psicologia. Cria-se um impasse e não se observa o envolvimento de Chomsky nas pesquisas da Psicolingüística, dedicando com os seus pressupostos iniciais à teoria lingüística.

A terceira fase denominada sociointeracionista surge em decorrência da insatisfação de alguns teóricos quanto ao modo de tratar os dados da fala infantil, sempre "encaixados" em categorias gramaticais formuladas pela teoria lingüística. Os dados da fala infantil com repetições da fala do adulto, incompletos, com erros, não eram considerados merecedores de análise linguiística. Ao realizar uma revisão crítica da história do sociointeracionismo, no qual se situa, Lemos (1986) demonstra que, nesta perspectiva, o outro passa a ter destaque, pois a linguagem da criança, justamente no seu aspecto de repetição da fala do adulto, é vista como dependente do outro. Um dos representantes dessa fase, Bruner (1957, apud Lemos 1994), inspirou-se nas reflexões de Vygotsky sobre a função da linguagem. Para este teórico a linguagem não teria somente a função de comunicação, mas, também, um papel na regulação da atividade conjunta. Nesse sentido, houve um retorno à Psicologia, pois são alçados os esquemas de interação entre a mãe e a criança no período pré-lingüístico, em que ocorreriam atividades de atenção e ação conjuntas, geralmente jogos ritualizados guiados pela mãe, onde a criança não só experiencia papéis sociais, como também segmenta as ações em papéis semânticos de agentivo, objetivo, entre outros, os quais terão este estatuto no período lingüístico sucessivo.

É o sociointeracionismo brasileiro de Cláudia Lemos que incorpora, de fato, o outro como tendo um papel estruturante na fala da criança, perspectiva ausente na proposta de Bruner. $\mathrm{Na}$ abordagem de Lemos, o sujeito psicológico cai por terra. Ao criar o conceito de processos dialógicos, C. Lemos ressignificou os erros da fala da criança, mostrando a sua dependência estrutural da fala do adulto. Dito de outra forma, muitos são os dados da fala infantil que puderam ser explicados pelo processo dialógico da especularidade, ou seja, como colagem na fala do seu interlocutor adulto. De qualquer forma, ela observou que existiam dados que faziam enigma e que interrogavam muitos aspectos da teoria que ela formulava. Nesse sentido, partindo da leitura que Lacan fez do estruturalismo europeu, representado por Saussure e Jakobson, C. Lemos inseriu o conceito de ordem própria da língua, de sujeito como efeito da língua, ou seja, nesta concepção a Lingüística retorna e a Psicologia se retira da Psicolingüística ( $c f$. Lemos, 1994). Aquilo que a criança diz, ainda que de maneira segmentada, encontra no diálogo uma matriz de significação, possibilitando, a posteriori, no espelhamento (onde a criança se vê e tem a sua fala refletida no fala da mãe) tornar-se fala. O outro não tem mais a função de fornecer a língua (porque alienado deste saber) ou de acionar um conhecimento lingüístico interno da criança, as categorias da língua. Passando a ser concebido como instância de funcionamento lingüístico-discursivo, como intérprete da fala da criança, conferindo-lhe forma, sentido e intenção, poder-se-ia imaginar a situação em que o adulto significativo para a criança se cala, fica em silêncio, e se perguntar, então, o que ocorreria? Registrar-se-á um enunciando à deriva, que não encontra ancoragem em um texto, que não tem história na fala do outro. Parece que o silêncio do outro frente às manifestações lingüísticas da criança pode responder a muitas das indagações da clínica fonoaudiológica que procura fora dela, da interação criança-mãe/ terapeuta, as explicações para as alterações de linguagem encontradas em crianças. 


\section{O DISCURSO MÉDICO E FONOAUDIOLÓGICO SOBRE O AUTISMO}

A síndrome autística foi descrita por Kanner na década de quarenta a partir da observação que realizou com onze crianças que tinham em comum o pouco contato social, em contraposição ao interesse demonstrado por objetos, desempenho intelectual não verbal elevado e origem familiar, em termos sócio-culturais, acima da média. Muitas mudanças ocorreram desde então, como a constatação de que o grupo de crianças acompanhado por Kanner era de alto desempenho (Síndrome de Asperger), em razão do tipo de clientela que ele atendia em seu ambulatório, não sendo, portanto, o protótipo que os estudiosos de hoje descrevem da síndrome, pois algumas das características apontadas por ele, a inteligência e a memória superiores à média, pertencem a um número restrito de crianças classificadas como autistas.

Atualmente, o autismo não é considerado uma entidade nosológica única nem reconhecido como tendo uma base etiológica única. São duas as causas do autismo levantadas pela literatura, alterações biológicas ou neurofisiológicas do organismo e fatores psicogênicos envolvidos na sua determinação, mas é a primeira que continua sendo, atualmente, a mais aceita. Isso se deve ao fato de haver estudos científicos procurando determinar, por meio de técnicas e instrumentos sofisticados, as alterações no funcionamento de determinadas substâncias/áreas do cérebro do autista.

No Manual de Diagnóstico e Estatística dos Transtornos Mentais (DSM IV), da década de noventa, é utilizada a nomenclatura de síndrome autística, considerada como um transtorno global do desenvolvimento, com surgimento nos três primeiros anos de vida da criança. A criança é assim diagnosticada quando apresenta quase metade de uma lista de sintomas bastante longa relacionada à dificuldade de interação, de linguagem e de conduta. Antes de relacionar os sintomas de linguagem descritos no transtorno autístico, é importante salientar que o advento das técnicas de investigação científicas objetivas têm tido o efeito de deslocar o autismo do grupo das psicoses para o de retardo mental, assim como de determinar que o tratamento destas crianças seja realizado na área de reabilitação, de preferência institucional, e não sob o enfoque das psicoterapias.

Oliver Sacks em seu livro Um Antropólogo em Marte - sete histórias paradoxais (1995) escreve uma narrativa, com título homônimo ao livro, contando a história de uma das mais famosas autistas do mundo, Temple Grandin, Ph. D. em ciência animal. Quando discute as causas do autismo, ele aponta para o fato de Kanner ter gerado toda uma geração de pais - particularmente mães - que se sentiu culpada pelo autismo dos filhos, ao apontar para as alterações na relação mãe e filho como fator etiológico preponderante. Sacks acredita na natureza orgânica do autismo, afirmando que as inúmeras pesquisas realizadas pela genética e pela biologia, a partir dos anos sessenta, puderam descartar o fator psicogênico da sua etiologia.

No discurso médico encontram-se os estudos estatísticos mostrando existir um número grande de crianças no grupo de autistas que possuem outras alterações associadas. Um dos poucos livros da área da Fonoaudiologia que aglutina vários trabalhos sobre autismo, Fonoaudiologia em Distúrbios Psiquiátricos da Infância (1995), organizado por Fernanda D. M. Fernandes, Lucila M. Pastorello, Cláudia I. Scheuer, faz referência à situação específica, no capítulo seis, em que crianças com uma deficiência primária, surdez, paralisia cerebral, entre outras, podem vir a desenvolver a psicose associada, que, muito mais do que a primeira, impede o desenvolvimento da criança. Especificamente nestes casos são buscadas no texto explicações da área psicanalítica, recorrendo-se a conceitos como o de ferida narcísea no imaginário dos pais, ou seja, os efeitos provocados pelo nascimento de uma criança que não correspondia à imagem de criança formulada pelos pais, referindo-se aos riscos de desenvolvimento de um quadro autístico na criança em decorrência da interação inicial mãe-filho.

As alterações de linguagem dos quadros autísticos são “... problemas graves quanto à compreensão de linguagem falada. A fala custa a aparecer e, quando isso acontece, nota-se ecolalia, uso inadequado de pronomes, estrutura gramatical imatura, inabilidade para usar termos abstratos. 
Há, também, uma incapacidade na utilização social tanto da linguagem verbal, como da corpórea..." (OMS, 1984, apud Fernandes, 1996). Alguns estudos (Baron-Cohen, Leslie e Frith, 1985) apontam para a dificuldade que os autistas teriam em representar as relações sociais, em realizar uma representação de uma representação, isto é, uma metarrepresentação. A dificuldade do autista residiria no fato de que possuiria uma percepção anormal para entender e prever o comportamento do outro, por isso os seus problemas de interação social.

Alguns autores tratam de diferenciar o autismo da psicose (Foster, 1999), aproximando da última o termo conduta autista da criança. Esta conduta seria decorrente do que o autor chama de fratura da função materna, em função das mais variadas dificuldades que podem surgir na interação mãe-filho (a), indo desde questões relativas ao nascimento de uma criança deficiente até as privações do contato da criança com a mãe em razão de internações prolongadas da criança (ou da mãe), enfim tudo aquilo que, nos termos de Albano (1990:23), não satisfaz as condições para a aquisição da linguagem, pois "crianças embrutecidas ou emocionalmente desorganizadas não aprendem a falar....Crianças negligenciadas ou severamente institucionalizadas acabam portadoras da síndrome do hospitalismo (Spitz, 1954) não aprendendo a falar...”. Da posição de neurologista, Foster, no trabalho referido, afirma que é de responsabilidade do médico fazer o diagnóstico da síndrome autística, como quadro único ou associado a outras doenças, assim como realizar a prevenção do autismo (conduta autística?), tendo em conta as situações que levam a criança a desconexões, como as internações prolongadas, já citadas, até a permanência da criança em creche por longas horas (?). As suas recomendações nessa direção não se aprofundam nas razões culturais, subjetivas e econômicas que levam às alterações na dinâmica da relação mãe-filho, mas, de certo modo, mostra a sua posição ideológica quando convoca o médico para "ensinar as pessoas a se oferecerem, em vez de oferecerem coisas" (Foster, 1999:260).

As referências encontradas na literatura sobre o jogo e a narrativa oral da criança autística são, em geral, semelhantes ao que se estabelece em termos de critérios diagnósticos de autismo infantil encontrados na OMS, em sua Classificação Internacional de Doenças (1984, apud Fernandes, 1996): “... ligação a objetos estranhos e um padrão de brincar estereotipado. A capacidade para pensamento abstrato simbólico ou para o jogo imaginativo fica diminuída...”.

Garcez (1995), em seu texto Narrativa em Crianças Psicóticas, afirma que uma abordagem pragmática da linguagem na terapia fonoaudiológica de crianças psicóticas, ou seja, a focalização do uso da linguagem intencional por estas crianças em situações comunicativas, permite considerá-las como interativas, diferentemente do que as abordagens fonoaudiológicas tradicionais postulam. Segundo a autora, o centro de interesse das investigações dela, e pode-se dizer do grupo de docentes/ fonoaudiólogos (as) vinculado ao Programa de Psiquiatria Infantil do curso de Fonoudiologia da FMUSP, é "a relação entre propostas comunicativas e o interlocutor" (p. 164). Neste artigo, a pesquisadora salienta que a análise das narrativas orais de duas crianças psicóticas é realizada também por meio do referencial teórico da análise do discurso, considerando que este enfoque "confere à dinâmica da interlocução uma posição de destaque dentro do contexto de interação" (p. 161).

Os dados apresentados no texto de Garcez referem-se a situações ocorridas entre as duas crianças em idade de alfabetização e entre uma delas e a fonoaudiológa. No primeiro caso, são reportados os diálogos entre as duas durante as brincadeiras e, no segundo caso, são transcritos os episódios nos quais uma das crianças relata à terapeuta o que aconteceu/acontecerá nas sessões conjuntas. Na sua análise de dados, Garcez chama atenção para os diferentes papéis assumidos pela criança dependendo da situação de interlocução: na primeira situação, as duas crianças assumem papéis fixos na brincadeira, uma é onipotente e a outra submissa; já na segunda, a criança que tinha um papel submisso passa a ter um papel mais ativo quando a situação dialógica é com a terapeuta. No entanto, parece que uma análise dos dados somente do ponto de vista dos papéis assumidos no 
diálogo parece não dar conta das mudanças ocorridas na linguagem dos sujeitos justamente por não apontar as marcas lingüísticas que permitem constatar tais mudanças.

Como Garcez utiliza o estudo de Perroni (1992) sobre o desenvolvimento do discurso narrativo, ela provavelmente esperava que as crianças, em idade de alfabetização, conseguissem produzir um discurso narrativo. De acordo com Perroni (op. cit.), a criança vai caminhando de uma fase inicial em que necessita da fala do outro para ancorar a sua narrativa (relato, caso, narrativa propriamente dita) até o momento em que passa a se constituir como narrador autônomo, sem ancoragem (explícita) na fala do outro. Perroni não acredita na existência de estágios no desenvolvimento da linguagem, mas observou, por meio do acompanhamento longitudinal realizado, que, por volta dos cinco anos, a criança conseguia narrar uma história sem a participação do seu interlocutor. Garcez muito provavelmente referiu-se ao aspecto cronológico quando afirma que as duas crianças não conseguem narrar histórias. Parece que a questão mais adequada a ser formulada seria com relação às práticas discursivas ocorridas entre os interlocutores, tanto entre as duas crianças como entre uma das crianças e a terapeuta: será que elas vivenciaram situações de contagem de histórias, por meio da manipulação de vários tipos de textos (gibis, livros de histórias infantis, entre outros) ou, ainda, tiveram oportunidade de ouvir a terapeuta ler/dramatizar histórias como as de contos de fada, por exemplo?

De qualquer maneira, vale destacar que a pesquisa relatada é uma das poucas na área que parte de um referencial diferente em termos de concepção de sujeito e de linguagem, já que a linha terapêutica mais adotada no acompanhamento de indivíduos autistas continua sendo a condutivista, baseada na teoria do condicionamento operante e no aumento de respostas por reforçamento positivo, como a versão Lovaas do método de ensaios incrementáveis e o programa TEACCH (Wobus, 1997).

\section{UMA ALTERNATIVA AOS ESTUDOS SOBRE A NARRATIVA ORAL NAS PSICOSES INFANTIS}

Dois artigos de áreas distintas da Lingüística, Lingüística Textual e Aquisição da Linguagem, um de Maria Elias Soares (1994) e outro de Cláudia Lemos (2002), é que possibilitaram uma reflexão sobre o estatuto da narrativa oral na linguagem de uma criança diagnosticada como psicótica. Por ocasião da avaliação e acompanhamento fonoaudiológico realizados desta criança, eu não tinha ainda claro a dimensão do alcance que as reflexões de C. Lemos sobre a aquisição da linguagem pela criança teria para a clínica fonoaudiológica.

Os conceitos de interação, de processos dialógicos, do papel fundamental do outro neste processo eram o que tinham efeito sobre a minha prática naquele momento. Os estudos em Neurolingüística, particularmente o marco inaugural da pesquisa dos distúrbios em linguagem sob a perspectiva discursiva, o livro de Maria Irma H. Coudry, O Diário de Narciso: discurso e afasia, de 1988, e, também, em Análise do Discurso, como o livro de Michel Pêcheux, O Discurso - Estrutura ou Acontecimento, de 1990, permitiram a minha reflexão sobre a linguagem em funcionamento. Tinha consciência que ao realizar atividades nas quais a subjetividade, a história do indivíduo não fosse alçada ou, ainda, o espaço terapêutico não se constituísse como um exercício vivo da linguagem, estaria repetindo atividades que tradicionalmente se fazia na clínica, quais sejam: apresentar lista de palavras para a criança repetir e figuras para ela nomear, entre outras. Considerei que ao construir práticas discursivas com a criança a partir daquilo que conseguia ouvir/escutar da sua história contada pela mãe, poderia sair do foco majoritariamente difundido na literatura sobre o autismo, destacando os erros, as incapacidades da criança na comunicação, na interação e no comportamento.

A criança com a qual trabalhei por três anos, a partir de agora JM, começou o acompanhamento fonoaudiológico por volta dos três anos e meio. O menino era primogênito e tinha um irmão menor sem problemas no desenvolvimento. JM, segundo a mãe, era uma criança normal antes de ter uma 
queda (mas sem conseqüências, pelo seu relato) quando tinha um ano; ele freqüentava uma creche em período integral desde o segundo ano de vida e ia a uma instituição de crianças com múltiplas deficiências três vezes por semana. A mãe tinha no seu imaginário uma explicação para o fato da criança não falar: ele tinha tido uma queda e, além disso, o marido não falava direito e tinha problemas de aprendizagem, como havia relatado sua sogra à ela. Como se vê, estes discursos circulavam pela família e acabavam constituindo a criança como não sendo capaz de falar.

Não caberia no propósito deste artigo relatar a entrevista e fazer uma análise rigorosa do discurso da mãe sobre as representações que a família tinha da criança e de sua linguagem, tampouco analisar o significado da doença do filho para a dinâmica familiar, mas fica o registro nesta passagem do artigo sobre a sua relevância na explicação de qualquer que seja a alteração de linguagem apresentada pela criança.

Mesmo no início do atendimento, quando a criança apresentava pouca oralidade, apenas algumas vocalizações e "palavras" como "cao" para carro e "mã" para mãe, tinha comportamentos ritualísticos (abrir e fechar as cortinas da sala de terapia repetidas vezes), usava o objeto sempre do mesmo modo (deslizava um carrinho para frente e para trás à frente do seu corpo quando estava sentado no chão), apresentava balanceio (rocking) e agitava os braços (flapping) diante de situações em que objetos se movimentavam, eu procurava criar situações de brincadeiras/faz-de-conta e, também, dramatizações de histórias infantis, procurando, na medida do possível, integrá-las àquilo que ele realizava solitariamente.

O episódio relatado abaixo ocorreu depois de dez meses de acompanhamento semanal de JM em sessões com duração de uma hora. A transcrição da sessão é ortográfica; procurei registrar as alterações fono-articulatórias de JM de maneira que o leitor possa ter idéia das mudanças ocorridas na fala de JM, lembrando que no início do processo terapêutico a sua oralidade era quase nula.

(Eu acabara de desenhar na lousa uma casa a seu pedido, quando, logo em seguida, JM toma o apagador das minhas mãos e apaga o desenho da casa)

$J M$. O cao.

T. Espera aí.

$J M$. Ó o cao. Ó o cao.

T. Vamos fazer aqui. A roda. Vamos fazer o carro. (Depois de fazer o contorno de um carro) Nossa que carro!

$J M$. O faol.

T. O farol. Isso. Que mais?

JM. O onbus.

T. O ônibus? Então você desenha. (Entrego um pedaço de giz a JM)

$J M$. (Ele faz pequenos rabiscos em um canto da lousa)

T. Puxa! esse ônibus está muito pequeno. (Referindo-me aos riscos bem pequenos feitos pela criança ao lado do carro)

$J M$. (Ele apaga o que fez)

$T$. Tem que ser grande, maior.

$J M$. Onbus. (Entregando-me o giz)

$T$. Vamos fazer maior. Faz maior. O ônibus está atrás do carro?

$J M$. (Faz um gesto afirmativo com a cabeça)

$T$. Então vamos fazer atrás do carro, certo?

$J M$. Motoíta. (Leva a minha mão em direção ao carro, no momento em que eu começava a desenhar o ônibus) 
T. Nossa, assim você me deixa perdida. Primeiro você quer o ônibus, depois você quer o motorista. Então vamos fazer o motorista aqui do carro. O motorista está dirigindo o carro. (Depois de feito o desenho) Pra onde ele está indo?

$J M$. Pra casa dele.

$T$. Pra casa dele?

JM. Pra casa dele.

O que se pode notar no diálogo é que eu repetia as palavras usadas por ele, por acreditar que, assim, estaria exercendo a função de conferir à sua fala forma, sentido e intenção. Apesar de ser uma situação atípica de narrativa de histórias, usando-se basicamente o desenho que eu fazia na lousa para contar histórias, constatou-se que os personagens, as ações foram sendo introduzidas desse modo no texto oral produzido pela criança. Da narrativa de uma história, passávamos para o relato, pois quem realizava as ações, muitas vezes, era o pai ou a mãe da criança, e daí, pouco a pouco, chegamos a narração de histórias infantis e ao faz-de-conta.

Do texto de C. Lemos (2002), destacarei uma passagem que revela o seu aprofundamento sobre o estatuto do diálogo no processo de aquisição/captura da linguagem e, também, sua reflexão sobre a questão de aquisição ulterior do texto relativamente às palavras, às frases da língua. Segundo a autora, a criança desde muito pequena ouve, reproduz, cria histórias, ou ainda, se vê cercada por histórias clássicas, folclóricas, familiares, tanto que ela argumenta contra a idéia de que o diálogo apareceria antes do texto. O outro ponto levantado na literatura corrente de aquisição, da precedência de palavras, de frases sobre o texto, não encontra respaldo nos dados da fala infantil, como bem evidenciam o diálogo do episódio transcrito acima: pode-se afirmar que há uma estrutura de texto permeando o diálogo em curso, no qual primeiro aparecem os personagens nomeados por ele (carro, ônibus, motorista) e a ação formulada por mim (indo para onde?).

Recortarei do texto de Soares (1994) a reprodução oral feita por uma das crianças da sua pesquisa, ressaltando que a perspectiva utilizada na análise da narrativa de uma criança considerada normal vem de outro lugar da Lingüística, a Lingüística Textual. A análise que a autora faz do texto da criança suprime julgamentos quanto à fidedignidade com relação ao que foi contado ou à introdução de elementos não relacionados ao texto, por exemplo. O seu interesse era verificar quais eram os recursos utilizados pelas crianças para a manutenção do sujeito temático e, também, verificar o emprego dos chamados delimitadores iniciais e finais da história; além disso, investigou as modificações desses procedimentos no período analisado por ela, dos três aos nove anos de idade.

“(16) Era uma vez um trenzinho muito esperto...Ele sorri, ele estava...com alegria de subir nos negócio [trilhos?]... levar assim um...muita criancinha, muita pedra...Saía muita fumaça e o trenzinho muito esperto "tava saindo fumaça. Ele é muito forte, num tem medo nem de ch...de sol...chuva..guarda-chuva...é muito forte...Ele é muito...muito...E ele...ele 'tava dormindo na casinha, dormindo, né. Ele sonhava que 'tava por aqui...um negocinho [refere-se ao balão que representa o sonho do trenzinho].

(Camila, 3;9)" (grifo meu)

Remeto ao leitor ao artigo da autora para os seus comentários sobre o texto da criança na perspectiva da Lingüística Textual. O que interessa destacar é o fato de que a palavra guarda-chuva aparece no texto da criança para deixar (se) ver o funcionamento lingüístico-discursivo atuando sobre a linguagem em constituição na criança. Há o deslizamento do significante, ou seja, a convocação pelo significante chuva da palavra guarda-chuva, alheia ao texto da história, mas não ao discurso familiar, do senso comum: em caso de chuva usa-se/deve-se usar o guarda-chuva. Ao que parece a criança retoma o que estava sendo narrado/descrito depois que essa palavra vem, pois no livro 
utilizado na pesquisa, e que as crianças manuseavam para reproduzir a história narrada pela pesquisadora, podia-se confundir a ilustração da fumaça do trem com uma nuvem, daí as hesitações, pausas nos trechos em que se encontram as palavras chuva e sol.

A discussão quanto ao estatuto da narrativa oral no desenvolvimento da linguagem de crianças no contexto patológico requer, com certeza, a continuidade destas reflexões, tanto com relação ao papel do terapeuta como àquilo que se conceitua como linguagem neste contexto. Procurei neste trabalho mostrar a possibilidade de mudanças qualitativas na fala de crianças psicóticas pelo viés de uma teoria e prática discursiva da linguagem.

\section{$\overline{\text { REFERÊNCIAS BIBLIOGRÁFICAS }}$}

ALBANO, E. C. (1990). Da Fala à Linguagem Tocando de Ouvido. São Paulo: Martins Fontes.

ARANTES, L. (1994). O Fonoaudiólogo, este aprendiz de feiticeiro. In: LIER-DE VITTO, M. F. (org.) Fonoaudiologia: no sentido da linguagem. São Paulo: Cortez.

BARON-COHEN, S.; LESLIE, A. M.; FRITH, U. (1985). Does the Autistic Child Have a "Theory of Mind"? Cognition, 21: 37-146.

BERBERIAN, A. P. (1995). Fonoaudiologia e Educação: Um Encontro Histórico. São Paulo: Plexus.

COUDRY, M. I. H. (1988). Diário de Narciso - discurso e afasia. São Paulo: Martins Fontes.

FERNANDES, F. D. M. (1996). Autismo Infantil: repensando o enfoque fonoaudiológico. São Paulo: Lovise.

FERNANDES, F. D. M.; PASTORELlO, L. M.; SCHEUER, C. I. (1995). Fonoaudiologia em Distúrbios Psiquiátricos da Infância. São Paulo: Lovise.

FOSTER, O. H. (1999). Autismo em Neurologia Infantil. In: JERUSALINSKY, A. e cols. Psicanálise e Desenvolvimento Infantil. Porto Alegre: Artes e Ofícios.

GARCEZ, I, F. C. (1995). Narrativa em Crianças Psicóticas. In: FERNANDES, F.; PASTORELLO, L. M.; SCHEUER, C. I. Fonoaudiologia em Distúrbios Psiquiátricos da Infância. São Paulo: Lovise.

LEMOS, C. T. G. de. (1986). Interacionismo e Aquisição de Linguagem. DELTA. São Paulo, EDUC, n. 2, p 1628.

(2002). Sobre o Estatuto Lingüístico e Discursivo da Narrativa na Fala da Criança. Campinas: [s.n.]. Inédito.

LEMOS, M. T. G. (1994). A língua que me falta: uma análise dos estudos em Aquisição de Linguagem. IEL/ UNICAMP. Tese de Doutorado.

PÊCHEUX, M. (1990). O discurso - estrutura ou acontecimento. Campinas: Pontes.

PERRONI, M. C. (1992). Desenvolvimento do Discurso Narrativo. São Paulo: Martins Fontes.

SACKS, O. (1995). Um Antropólogo em Marte- sete histórias paradoxais. São Paulo: Companhia das Letras.

SOARES, M. E. (1994). Aspectos Relativos à Produção de Narrativas por Crianças de 3 a 9 anos in: Cadernos de Estudos Lingüísticos, Campinas, IEL/UNICAMP n.26, p.79-102.

WOBUS, J. (18/12/02)). Perguntas más Frecuentes sobre Autismo, Autismo. Espanha. disponível em http:// www. autismo.com/scripts/articulo/1997-/htm>. 